\title{
Must overlearned lists be scanned?
}

\author{
CHARLES CLIFTON, JR.* \\ University of Massachusetts, Amherst, Massachusetts 01002
}

\begin{abstract}
Ss were presented given names as test items and asked either to indicate whether each test name was a member of a previously memorized list of names or whether each test name was the name of one of their siblings. The data indicated that the memorized list of names was scanned in a serial fashion but that (disregarding the case where $S$ had just one sibling) $S$ did not have to scan the list of his own siblings' names to decide about a test name.
\end{abstract}

When one is to decide whether a test item is a member of a previously memorized short list of items, one apparently compares the test item against each of the remembered items in a serial fashion (Sternberg, 1966, 1969). This serial exhaustive scanning process seems to occur for lists that were learned immediately before the test item. as well as for lists that were learned several minutes previously and which received over 100 test trials (Sternberg, 1966, Experiment 2). The present experiment was designed to determine whether such a serial scanning process is used to determine the membership of lists of items that Ss have known for a period of years.

Kriska and Erickson (1972) presented evidence that well-known sets of items, up to perhaps seven in length, may be scanned serially. They found that time taken to indicate whether a test word was a member of a natural category of Sizes 2 to 50 (e.g., a category of Size 2 would be the category "male, female"; a category of Size 4 would be the points of the compass) increased with increase in category size from two to seven, but was relatively flat thereafter. However, the increase found by Kriska and Erickson was quite irregular, and in their experiment, category size is very likely confounded with other variables, such as word length, word frequency, and phonemic makeup of words.

The present experiment eliminated such confounding factors by using the set of names of the S's siblings as the well-learned target set. An S saw individual names as test words and was to respond "yes" when a test word was the name of one of his siblings. If Ss can directly access the members of such a well-known target set. reaction time (RT) should not increase with an increase in its length. On the other hand, if Ss continue to scan such a list in a serial fashion, RT should increase linearly with length, and the slope of the increasing function can be interpreted as the duration of a comparison between the probe and an individual member of the list.

The design of this experiment necessarily makes the size of the memorized list a between-S factor, an

\footnotetext{
*I would like to thank Tom Borkowski and Steve Torosian for collecting the data reported here. Requests for reprints should be sent to Charles Clifton. Department of Psychology. University of Massachusetts. Amherst. Massachusetts 01002.
}

undesirable characteristic in RT experiments. However, the problems thus introduced were minimized by testing a reasonably large number of $S s$ in each experimental condition, and a partial control was introduced by testing each $\mathrm{S}$ on a list of randomly chosen names (which he would be expected to scan serially), as well as on the list of his siblings' names.

\section{METHOD}

\section{Subjects}

Undergraduate volunteers with one to four siblings were recruited at the University of Massachusetts. It proved difficult, even in Massachusetts, to find adequate numbers of Ss with large families. Thus. 20 Ss were tested who had one brother or sister, 17 who had two. 16 who had three, and 11 who had four. Before the experiment, Ss were asked for the names they generally called their siblings, which were typed and photographed.

\section{Procedure}

Each $S$ was tested for two series of 120 trials, one series involving the names of his siblings (Condition Sib) and one series involving randomly selected names (Condition $\mathrm{Ran}$ ). Each series was divided into five blocks of 24 trials. Approximately half of the Ss within each family size were tested first in Condition Sib and half in Condition Ran.

Prior to the beginning of a series, $\mathrm{S}$ was given the list of names he was to consider first as a target set. The list was either the list of his siblings' names or an equally long list of names chosen from a pool of 210 names. The $S$ was instructed further that he would see 120 individual test names and had to pull a lever with his right index finger if a test name was in the target set and another lever with his left index finger if it was not. He was also briefly shown the list of names (whose length was 13 minus the number of his siblings) which would appear as test items not in the target set. These negative instances were chosen randomly. except that an S's siblings' names did not appear in them and the lists of negative instances an $S$ received in Condition $S i b$ and $R$ an did not overlap.

On each trial, a single name was projected approximately $1.5 \mathrm{~m}$ from $\mathrm{S}$ (visual angle for a five-letter name was $2.5 \mathrm{deg}$ ) by a Kodak RA 960 projector equipped with a Gerbrands tachistoscopic shutter. Slides were selected randomly, with the restriction that there were 12 positive probes in each trial block. As soon as $\mathrm{S}$ had pulled a response lever, the slide was removed. Reaction time was measured to the nearest millisecond. A green signal lamp was lit if $S$ 's response had been fast (less than $512 \mathrm{msec}$ ) and correct and an amber error light if it had been incorrect. Approximately $2.5 \mathrm{sec}$ later. the next trial began. Ss were informed after each trial block of the number of errors and 


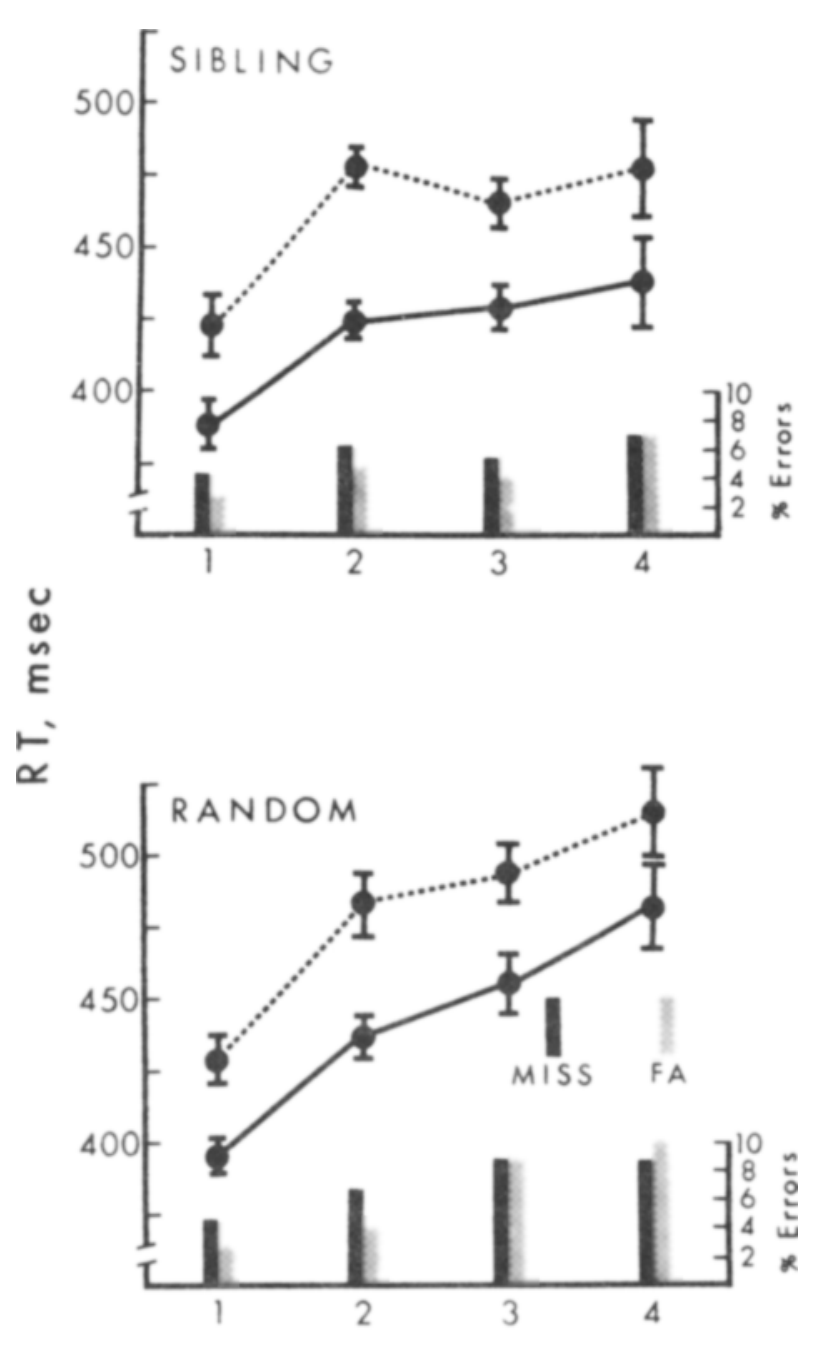

SET SIZE

Fig. 1. Reaction time as a function of target set size, with standard errors of RT and error rates indicated. (Solid lines represent positive probe $\mathrm{RT}$, dashed lines are negative probe RT.)

fast correct responses they had made. At the end of the first series of 120 trials, $S$ was instructed in the nature of the other experimental condition ( $\mathrm{Sib}$ or Ran), and the procedure described was repeated.

\section{RESULTS}

The mean RTs are presented in Fig. 1, together with their standard errors and the error rates. While the latter are fairly high, reaching $10 \%$ in one condition, they are relatively constant over experimental conditions and probably do not cause problems in interpreting the RT data.

The RTs for Condition Ran rise monotonically with the size of the target set (set size). A straight line fitted to these data (least-squares criterion) has a slope of $27.5 \mathrm{msec} / \mathrm{item}$, well within the range of reported memory scanning rates. However, inspection of Fig. 1 indicates that RTs to Set Size 1 are faster than would be expected by linear extrapolation from the remaining points. Such deviantly fast Set Size 1 RTs are quite commonly found (though less frequently commented upon), particularly for positive responses (Sternberg, 1966, Experiment 1; 1969, Experiment 5: Clifton \& Birenbaum, 1970; Nickerson, 1966; Egeth \& Smith, 1967: Forrin \& Morin, 1969; Marcel, 1970; Clifton, several unpublished experiments using the procedure in which each memorized set is tested repeatedly). A straight line fitted to the RTs for Set Sizes 2.4 has a slope of $19.0 \mathrm{msec} / \mathrm{item}$, close in magnitude to previously reported scanning rates.

The deviant rapidity of Set Size 1 responses is very apparent in the data for Condition Sib. Reaction time rises $47 \mathrm{msec}$ from Set Size 1 to Set Size 2, but only $3.5 \mathrm{msec} /$ item (slope of the fitted straight line) thereafter. The rise from Set Size 1 to 2 closely approximates the rise for Condition Ran $(49 \mathrm{msec})$, while the rise from Set Size 2 to 4 is much smaller.

Because of the apparent deviance of the Set Size 1 data, unweighted means analyses of variance with set size, condition, and response as factors were performed separately for Set Sizes 1 and 2 and for Set Sizes 2 to 4 In the former analysis, the effect of set size was significant $[F(1,35)=24.75, p<.01]$, as was the effect of responses $[F(1,35)=105.7, p<.01]$. No other effects or interactions reached significance; in particular, the conditions effect ( $\mathrm{Sib}$ vs Ran) had an $\mathrm{F}(1.35)$ of $2.44, p>10$, and the interactions involving the conditions effect were associated with Fs less than 1.

In the analysis of Set Sizes 2 to 4 , the effect of set size was significant $[F(2,41)=3.88, p<.05]$. Again, positive responses were faster than negative responses $[\mathrm{F}(1,41)=117.6, \mathrm{p}<.01]$, and again the response factor did not enter into any significant interactions. Unlike the previous analysis, the interaction between conditions and set size was significant $[F(1,41)=5.94$. $p<.01]$. Simple effects tests showed that the effect of set size was significant for Condition $\operatorname{Ran}(p<.01)$ but not for Condition Sib $(\mathrm{F}<1)$.

\section{DISCUSSION}

The implications which the data have for the question of how information about very well-learned sets of items are retrieved depend upon the interpretation of the Set Size 1 data. The references cited earlier lead one to suspect that different processes may influence responses to probes of Set Size 1 than responses to probes of larger set sizes. The present data can also be interpreted as indicating, even more strongly than previous reports, that responses to Set Size 1 probes are deviant. The increase in RT from Set Size 1 to Set Size 2 was not influenced by the degree to which the target set was learned, while the increase in RT with further increases in set size was markedly influenced by degree 
of learning. An account of such an interaction could, perhaps, be built upon the claim that decisions involving Set Size 1 are based upon comparisons of visual forms, while decisions involving larger set sizes are based upon comparisons of more abstract representations of remembered and test items. Alternatively, it might be possible to build such an account upon the claim that, in the Set Size 1 case, attention can be focused upon the single remembered item, while, for larger set sizes, attention must be directed to some sort of an entry point into memory.

If one grants that RTs to Set Size 1 are not directly relevant to the issue of whether overlearned sets of items are scanned, then the present data lead one to conclude that very well-learned sets of items are not scanned in a serial fashion (or are scanned at a rate which is experimentally almost impossible to measure for small set sizes; cf. Landauer \& Freedman, 1968). While RT increased at a rate of $19 \mathrm{msec} /$ item between groups of Ss who were tested on sets of two to four randomly chosen names, it increased an insignificant $3.5 \mathrm{msec} /$ item between the same Ss when they were tested on sets consisting of their brothers' and sisters' names. One might suggest a threefold distinction among modes of storing information in memory. First, items which have just been presented (as in Sternberg's, 1966, varied set procedure) exist in an active memory, in which they can be serially scanned. Second, sets of items which had been learned in the relatively recent past (such as the sets of randomly chosen names in the present experiment) are linked together in a more permanent memory. By virtue of these links, they may be brought into active memory (in the present experiment, generally before a test item is presented), in which they are scanned.

Finally, very well-known information about a word can be directly represented in the mental lexical entry for that word; for instance, each of one's lexical entries for the names of his siblings contains the information that it is a sibling name. Lexical entries can be directly addressed, on the basis of their phonological and perhaps other content. Thus, the information needed to determine whether a test name is a member of the set of one's siblings can be obtained without scanning all the members of that set.

\section{REFERENCES}

Clifton, C., Jr., \& Birenbaum, S. Effect of serial position and delay of probe in a memory scan task. Journal of Experimental Psychology, 1970, 86, 69-76.

Egeth, H., \& Smith, E. E. On the nature of errors in a choice reaction task. Psychonomic Science, 1967, 8, 345-346.

Forrin, B., \& Morin, R. E. Recognition times for items in shortand long-term memory. Acta Psychologica, 1969, 30, 126-141.

Kriska, D., \& Erickson, J. R. Long-term memory search as a function of category size and presentation time. Paper presented at Midwestern Psychological Association, Cleveland, May 1972.

Landauer, T. K., \& Freedman, J. L. Information retrieval from long-term memory: Category size and recognition time. Journal of Verbal Learning \& Verbal Behavior, 1968, 7, 291-295.

Marcel, A. J. Some constraints on sequential and parallel processing, and the limits of attention. Acta Psychologica, $1970,33,77-92$.

Nickerson, R. S. Response times with a memory-dependent decision task. Journal of Experimental Psychology, 1966, 72, 761-769.

Sternberg, S. High-speed scanning in human memory. Science, $1966,153,652-654$.

Sternberg, S. Memory-scanning: Mental processes revealed by reaction-time experiments. American Scientist, 1969, 57 , 421-457.

(Received for publication October 1, 1972; revision received December 2, 1972.) 